\title{
EDITORIAL
}

\section{Puertas abiertas I puertas cerradas: los refugiados ponen en evidencia a Europa}

\section{Consejo de Redacción}

Resumen: En este editorial queremos pronunciarnos sobre la llamada "crisis de los refugiados". En primer lugar debemos aclarar cuestiones como el impacto de la llegada de refugiados a nuestro entorno europeo. Este hecho pone de relieve la crisis del proyecto europeo. La diferenciación, importante, porosa y no siempre clara, pero necesaria, entre refugiados (en sentido humanitario) e inmigrantes (en sentido económico) nos ha parecido necesaria para poder poner de relieve lo central que está en juego en ambas "crisis": por un lado, los países empobrecidos que padecen las consecuencias de guerras, hambrunas, gobiernos dictatoriales, sobreexplotación y acaparamiento de recursos por parte de poderes económicos o políticos extraños a sus pueblos; por otro, la crisis de valores y de principios que revela en Europa este problema demográfico humanitario. Nuestra posición, además de una mirada autocrítica sobre la realidad, quiere servir para proponer algunos compromisos explícitos de acción: políticas de acogida que sean eficientes en la integración de los refugiados, respetuosas de los derechos humanos y sostenibles en las sociedades europeas. ${ }^{1}$

Palabras clave: Convención de Ginebra (195I), crisis de los refugiados, desplazados internos, flujos mixtos, migración forzada, migración mixta, migración voluntaria, planeta móvil, refugiados, solicitantes de asilo.

Fecha de aprobación: 3 de octubre de 2016.

\footnotetext{
' Estando ya en imprenta este número, cuatrocientas entidades españolas entre las que casi una cuarta parte muy relacionadas con la Compañía de Jesús, publicaron una Solicitud al Gobierno de España y a la Comisión Europea Para que no se mueran de frío: la Unión Europea debe cumplir el deber de socorro, que incluimos en la sección de Documentos.
} 
Doors open / closed doors: refugees show Europe up

\begin{abstract}
In this editorial comment, we take a position on the so-called "crisis of the refugees". First, there are issues that need to be clarified such as the impact of the arrival of refugees to the European environment. This fact highlights the crisis of the European project. We consider the important and porous distinction, not always clear, but necessary, between refugees (in humanitarian sense) and immigrants (in the economic sense) to be necessary to highlight the fundamental aspects which are at stake during these "crises". On the one hand, the crisis of impoverished countries which suffer from the consequences of wars, famines, dictatorial governments, overexploitation and hoarding of funds by economic or political powers foreign to their villages; on the other hand, the crisis of values and principles that reveals this humanitarian demographic problem in Europe. Our position, besides being a self-critical look at reality, intends to propose clear commitments to action efficient reception policies to integrate refugees that respect human rights and that are sustainable in European societies and which are based on critical thoughts on the ethical paradigms of performance, the more acceptable and the most problematic.
\end{abstract}

Keywords: Geneva Convention (I 95 I), crisis of the refugees, internal displacement, mixed flows, forced migration, mixed migration, voluntary migration, mobile planet, refugees, asylum-seekers.
Portes ouvertes / portes fermées: les réfugiés mettent en évidence l'Europe

Résumé: Dans cet éditorial nous voulons nous prononcer sur la soi-disant «crise des réfugiés». Tout d'abord, nous avons besoin de clarifier des questions telles que l'impact de l'afflux de réfugiés en Europe. Ce fait met en évidence la crise du projeteuropéen. Nous avons cru nécessaire établir la différence, importante, poreuse, et pas toujours si claire, mais nécessaire, entre les réfugiés (au sens humanitaire) et les immigrés (au sens économique) afin de mettre en évidence ce qui est central et ce qui est mis en jeu dans ces «crises». D'une part, la crise des pays pauvres qui subissent les conséquences de guerres, de famines, de gouvernements dictatoriaux, de surexploitation et d'accaparement de ressources par des puissances économiques ou politiques étrangères aux populations autochtones; d'autre part, la crise de valeurs et de principes que ce problème démographique humanitaire révèle en Europe. Notre position, avec de plus un regard autocritique sur notre réalité apparente, veut être utile pour proposer des engagements explicites à l'action: politiques d'accueil qui soient efficaces pour I'intégration des réfugiés, respectueuses des droits humains et qui soient durables dans les sociétés européennes, en partant d'une réflexion critique sur les paradigmes éthiques, aussi bien les plus acceptables que ceux qui deviennent les plus problématiques

Mots clé: Convention de Genève (195I), crise des réfugiés, personnes déplacées dans leur propre pays, flux mixtes, migration forcée, migration mixte, migration volontaire, planète mobile, réfugiés, demandeurs d'asile. 
Os agradezco que os hayáis planteado las difíciles cuestiones de la acogida a los refugiados. Gracias a la educación recibida de los jesuitas se os han abierto muchas puertas, mientras los refugiados encuentran muchas puertas cerradas. ${ }^{2}$

El desterramiento deviene un destino universal. ${ }^{3}$

\section{I.Introducción: la "crisis de los refugiados" es una crisis de Europa ${ }^{4}$}

Nos hemos acostumbrado a la expresión "crisis de los refugiados", pero muchas veces no está claro a qué nos referimos. Para algunos, entre los que nos contamos, no hay tal crisis padecida por Europa, pues ni se trata de una invasión (... aunque algunos lo quieren presentar así), ni somos los que sufrimos directamente las consecuencias de los desplazamientos que afectan a 65 millones de seres humanos 5 en el mundo actual, que se han visto obligados a dejar sus tierras y desplazarse a otros países. Los refugiados y desplazados hoy forman uno de los "países" mayores de la tierra, con una población comparable a cualquiera de tres de los mayores Estados europeos como Italia, Francia o Reino Unido. Es ciertamente un número impresionante, pero se trata sobre todo de mujeres, hombres, niños o ancianos, no diferentes de las personas de nuestras familias o de nuestros entornos, con un derecho inalienable a vivir en paz y a aspirar a un futuro mejor para sus propios hijos.

\footnotetext{
${ }^{2}$ Papa Francisco a los participantes en el Encuentro promovido por la Unión mundial y la Conferencia europea de exalumnos de los jesuitas y co-organizado por el JeSUIT Refugee SERVICE (JRS), Roma, 17IX-2016. http://w2.vatican.va (consulta 21-IX-2016).

${ }^{3}$ M. Heidegger, Carta sobre el Humanismo.

${ }^{4}$ Como otras veces, en el origen de este editorial ha habido un par de seminarios internos, celebrados respectivamente el 10 y el 18 mayo: con la participación de Carlos Arce y de Francisco García-Calabrés, ambos profesores de la Universidad Loyola y especialistas en varias dimensiones de este tema, tuvimos una primera sesión celebrada en Córdoba, y con la participación de Francisco Abredor, experto de Cáritas Madrid, celebramos una segunda sesión en Sevilla. A ellos vaya nuestro agradecimiento, dejando constancia de que la responsabilidad de las opiniones y de los posibles errores es exclusivamente nuestra.

${ }^{5} \mathrm{Si}$ en 2005 el total de personas desarraigadas era de 37,5 millones de personas, nueve años después, el Informe anual de la agencia de Naciones Unidas para los refugiados (ACNUR/UNHCR) elevaba el total a 59.500.000 de personas desarraigadas: 38,2 millones de desplazados internos, 1,8 millones de solicitantes de asilo y 19,5 millones de refugiados en sentido estricto y, sólo dos años más tarde eran casi un 10\% más: 65 millones de personas (de ellos 28 millones de niños, a los que sumar 20 millones de niños migrantes). El planeta móvil de los desarraigados en 2016 lo compone un $64 \%$ de desplazados internos (40,5 millones), un $3 \%$ de solicitantes de asilo (3 millones) y un $33 \%$ de refugiados (21,5 millones), según la nota de prensa del Jesuit Refugee Service (JRS) de 20-IX-2016.
} 
El objetivo de este editorial es poner de manifiesto que el hecho de los refugiados es una realidad estructural en cuyo origen hay causas de larga duración; si tenemos que hablar de alguna crisis, no es de una "crisis de los refugiados" sino de una crisis de valores y, en concreto, de una "crisis de la protección de los derechos humanos" en Europa. ${ }^{6}$ En nuestra perspectiva, Europa tiene un protagonismo importante, pero no único. Los datos y definiciones que hemos aportado anteriormente nos ponían sobre la pista de que en Europa la realidad de los refugiados, sin restarle un ápice de su dureza, se ha ponderado mal, trasladando a la ciudadanía una imagen desproporcionada del tema. Nuestra mirada necesita, por tanto, proporción y perspectiva. La verdadera crisis humanitaria y demográfica de los refugiados la padecen intensa e inmediatamente los países de origen de los mismos: los refugiados que han huido recientemente de sus países son casi cuatro millones de sirios, más de dos millones y medio de afganos, un millón doscientos mil en Somalia y otros tantos entre ambos Sudán y Sudán del Sur. Si a estos tres grupos africanos sumásemos los refugiados procedentes de la República Democrática de Congo, de República Centroafricana y de Eritrea, en África centro-oriental llegaríamos a sumar un total de más de tres millones y medio (3.680.000) de refugiados (datos de 2014).

Es cierto que los refugiados sirios son la mayor minoría (3.884.000, datos de 2014), a la que siguen los procedentes de Afganistán y Somalia; también son los que han alcanzado más visibilidad. Siria ocupa el primer lugar en el número de desplazados internos (5.210.000, datos de 2013), seguida de Colombia, República democrática de Congo, Sudán (y Sudán del Sur) y Somalia, todos esos países con más de un millón de desplazados internos. Casi el $20 \%$ de los refugiados mundiales procede de Siria, estando la mitad de ellos en Turquía y el resto entre la población más desfavorecida de países pobres de su entorno: además de los desplazados internos en la propia Siria y los señalados en Turquía, el resto se concentra en Líbano7 o Jordania.

\footnotetext{
"Un punto de visa interesante y complementario del nuestro: J. DE LUCAS (2016) "La UE pierde su alma ante los refugiados": Éxodo, n' 134 (junio), 26-31, del mismo autor, catedrático de Filosofía del derecho y Filosofía política en la Universitat de València, J. DE LUCAS (2016) Mediterráneo: el naufragio de Europa (2015), Valencia, Tirant lo Blanch; por otra parte es interesante la lectura de S. Žlžek (2016) La nueva lucha de clases. Los refugiados y el terror [Londres 2016], Barcelona, Anagrama.

7 En este país, más de un millón doscientos mil refugiados, mayoritariamente en el valle de la Bekaa, suponen el $25 \%$ de la población de un Estado de algo más de 4 millones; más del 70 por ciento de estos refugiados sirios vive por debajo del umbral de la pobreza y más del 50 por ciento necesita una mejora urgente de su alojamiento. A pesar de lo cual, gracias a la ayuda internacional según ACNUR en Líbano, la situación económica de los refugiados no es tan grave como en 2015. No obstante, el primer ministro libanés, Tammam Salam, considera urgente un plan para el "retorno seguro" de los refugiados a Siria y "grave" el riesgo de "colapso" para la estabilidad, seguridad y economía del país.
} 
Según ACNUR el $86 \%$ de los refugiados del mundo están en los países empobrecidos y entre los diez primeros países acogedores de refugiados no hay ningún Estado europeo. Ciertamente esta crisis no es un problema europeo ni en su origen ni en sus efectos inmediatos.

Pero creemos que este hecho mayor de nuestro tiempo sí provoca una crisis en nuestro entorno, pues nos plantea la pregunta sobre la Europa que queremos, ya que es una ocasión para afrontar la crisis del proyecto europeo en algunos de sus trazos esenciales: hospitalidad, paz, equidad, protección de los derechos fundamentales. Éste va a ser el punto de partida de nuestro editorial: reflexionaremos sobre esta crisis europea de los derechos humanos. Para algunos, desde posiciones diferentes, Europa está perdiendo su alma ante los refugiados.

El hecho de los refugiados se sitúa en un contexto demográficamente mucho mayor que no es en absoluto ajeno y muchas veces se confunde con el otro aspecto, relacionado pero diferente: las migraciones mundiales que forman parte del que se ha llamado planeta móvil, una realidad estructural de nuestro mundo. No podemos, pues, quedarnos sólo en la primera dimensión o fase de emergencia del problema de los refugiados, sino que hemos de dar espacio a los problemas reales que explican las causas de las migraciones, los cambios producidos y las consecuencias para las personas y para los pueblos. No estamos ante un hecho ocasional ni periférico, sino ante una dimensión estructurante de nuestra configuración social y demográfica mundial. Pero a la vez hemos de distinguir claramente ambas realidades, siendo el de los refugiados un problema más grave y urgente.

Por otro lado, es cierto que, junto al cambio estructural, sigue habiendo crisis humanitarias urgentes que interpelan a nuestra conciencia humana en muchos casos, aunque en otros muchos se detienen en una hiriente indiferencia sin otro resultado final que la complicidad silenciosa de quienes se consideran meros espectadores pasivos. El planeta móvil-desplazados, solicitantes de asilo, refugiados o emigrantes- es un hecho de larga duración ${ }^{8}$ y una realidad compleja que sólo puede ser abordada desde un análisis poliédrico.

${ }^{8}$ Cf. E. MoYAno (2015) "La Unión europea ante la inmigración": RFS 70, 281-292. Además de este artículo, señalamos entre otros textos breves, claros y válidos para formar una opinión: $M$. González MARTín (2015) De la hostilidad a la hospitalidad, Barcelona, Cristianisme i Justicia (Cuaderno CiJ 196, noviembre, también hay versión catalana e inglesa: https://cristianismeijusticia. net/es/quaderns), 32 pp.; À. RodRíGuez, editor (2015) "Refugiados. Otro proyecto que desafía a Europa": Vanguardia Dossier ( ${ }^{\circ} 58$ octubre), 98 pp.; CONSELL ASSESSOR PER A LA DiverSitAT Religiosa de la Generaltat de Catalunya (2015) Acollir el foraster. L'hospitalitat com a deure i actitud espiritual (traducción castellana, 2016), 67 pp. (documento muy inspirador, punto de vista cultural-religioso). 
En un primer momento queremos precisar algunas palabras que nos ayudarán a desenvolvernos con más claridad en el resto del editorial. Por eso nos atrevemos a definir los términos. Los desplazados internos son aquellos que por razones de seguridad o de protección abandonan su hogar o su tierra, desplazándose dentro del mismo país o Estado del que forman parte. Los refugiados son aquellas personas que buscan un lugar de acogida -y lo encuentran- fuera de su país, huyendo de una situación de guerra, revolución, persecución étnica, política ideológica o religiosa, porque ven amenazados sus derechos humanos esenciales. Los solicitantes de asilo son aquellos migrantes o refugiados que dicen necesitar protección internacional pero ante quienes las autoridades de uno o más Estados no han adoptado una decisión de acogida. Por último, migrantes son aquellas personas o grupos, familiares o étnicos, que por problemas económicos se trasladan de país, Estado o región, en busca de una forma estable temporal que les permita mejorar su nivel de vida (si se desplazan dentro del mismo país o Estado los consideramos migrantes interiores).

Después de esta introducción en la que hemos precisado algunos términos usados, nos detendremos en una parte descriptiva, a continuación analizaremos esta realidad compleja y poliédrica y finalmente trataremos de ofrecer algunas claves de interpretación y criterios para orientar una respuesta posible.

\section{Descripción y análisis de un problema poliédrico}

Si las definiciones anteriores parecen claras, nos permitiremos ahora dar cuenta de la ambigüedad y porosidad semántica de estas realidades, lo que no nos exime de la necesaria claridad. Éste es precisamente el servicio que pretendemos prestar para analizar honestamente esta realidad compleja y poliédrica.

\section{I. Las llamadas migraciones mixtas}

En los últimos decenios se está considerando la pertinencia de un nuevo concepto de migración mixła (Mixed migration, Nicholas Van Hear). En las motivaciones de las personas que emigran pueden confluir la huida de conflictos bélicos y el deseo de llegar a países con mayores posibilidades económicas.

En efecto hoy se habla de migración mixta: una forma de migración que recoge elementos de la migración forzada (de subsistencia humanitaria) y de la migración voluntaria (económica en búsqueda de mejor nivel de vida). La frontera entre una y 
otra forma es porosa, con amplias zonas intermedias, grises o híbridas. No siempre resulta fácil diferenciar entre los desplazamientos en búsqueda de una mejora económica (migraciones en sentido original) de aquellos otros desplazamientos que, aun teniendo razones primordialmente económicas y no siendo estrictamente movimientos de refugiados, están producidos por reacción a revueltas armadas desestabilizadoras en el entorno, catástrofes naturales o emergencias ambientales, pobreza severa crónica, procesos duraderos de desertificación de tierras cultivables o con pastos insuficientes, agotamiento de recursos naturales, privatizaciones de recursos hídricos o explotación por violencia infantil y juvenil (pandillas, "maras") o sexista contra la mujer. A estos hay que añadir recientemente los conocidos como refugiados por cambio de régimen, especialmente desde la destrucción del Estado iraquí y de la frustrada primavera árabe en el Mediterráneo sur y su crisis posterior. Por todo ello hoy se habla cada vez con más frecuencia de flujos mixtos pues en ellos los refugiados en sentido estricto y los migrantes forzosos, si por un lado parten de distinta motivación y tienen distintas necesidades de protección, de hecho viajan juntos por las mismas rutas, utilizan los mismos medios de transporte y las mismas redes o "mafias" de traficantes y buscan los mismos destinos."

La distinción entre refugiado y migrante no es terminantemente clara, pero tampoco irrelevante. La confusión entre refugiados y migrantes puede tener graves consecuencias para la vida y la seguridad de unos y otros. Ser o no ser reconocido como refugiadotiene efectos importantes en los mismos como personas. Si distinguir con demasiada claridad y rigidez entre migrantes y refugiados sería discutible e injusto, no distinguir de ninguna manera también lo es, pues provocaría otro tipo de reacciones de rechazo ante la falta de claridad y de rigor, pues las dimensiones y características "típicas" de una y otra situación (migrante/refugiado) muchas veces son diferentes. En realidad estamos ante un proceso en que las distinciones se contaminan, pero seguimos necesitándolas. Esta deliberada o accidentada confusión y el deslizamiento semántico de los conceptos hacen comprensible que recientemente ACNUR haya defendido la pertinencia de la distinción entre refugiado y migrante para consolidar la posición oficial de tutela de los prófugos y refugiados, evitando el vaciamiento del derecho de asilo por un uso instrumental de éste que haría perder su contenido esencial. ${ }^{10}$ Las dos palabras tienen significados

9 Cf. E. Roman (2015) "¿Migrantes o refugiados?: crisis de una distinción y de las políticas": La Vanguardia. Dossier, n. 58 (octubre), 34-41 (38).

$10 \mathrm{Cf}$. Adrian EDWARDS «Réfugié» ou «migrant» - Quel est le mot juste? (UNHCR, Ginebra (CH), 12 VII-2016, original 27-VIII-2015; http://www.unhcr.org/55df0e556.html (disponible también en inglés, consulta el 23-IX-2016). ACNUR llama "refugiados" a quienes huyen de la guerra o la persecución 
distintos y diferentes, por lo que confundir su uso perjudica a ambos colectivos. Para ACNUR hay una diferencia y es importante; utilizar los términos refugiado y migrante erróneamente no ayuda a resolver los problemas de ambas poblaciones.

\subsection{La condición de refugiado}

Rechazar el asilo a los refugiados, personas en situación peligrosa e intolerable, tratándoles como inmigrantes que podrían -e incluso eventualmente deberíanser repatriados tendría "consecuencias potencialmente mortales" (Edwards), pero desconocer los derechos específicos y diferentes de los migrantes, pretendiéndoles "proteger" como refugiados, contribuiría a empeorar también su capacidad de movilidad, de integración y de mejora de nivel de vida con perspectivas de ascenso social, al tiempo que contaminaría la protección de los derechos fundamentales de los refugiados.

El término refugiado fue definido por la Convención de Ginebra sobre el Estatuto de los Refugiados (1951) como el que conviene a aquella persona que

debido a fundados temores de ser perseguida por motivos de raza, religión, nacionalidad, pertenencia a determinado grupo social u opiniones políticas, se encuentra fuera del país de su nacionalidad y no puede o no quiere acogerse a la protección de tal país o no quiere regresar a él a causa de dichos temores ${ }^{11}$.

por el cruce de una frontera internacional y llama "migrantes" a las personas que se desplazan por razones que no están incluidas en la definición legal de refugiado. Para ACNUR la elección de las palabras es importante.

"La previsión del derecho internacional vigente en esta materia es amplia y tiene un largo recorrido: Declaración universal de Derechos humanos de 1948 (art. 14); Convención de Ginebra sobre el Estatuto de los Refugiados de 1951 (art. 33); Protocolo de Nueva York de 1967; Convención de Derechos del Niño de 1989 (art. 22); Carta de Derechos Fundamentales de la UE (art. 18 y 19). En el ámbito europeo hay que hacer referencia también al Consejo Europeo de Tampere de 1999, que impulsó la creación de un sistema europeo común de asilo; Directiva 2003/86/CE del Consejo de 22-IX-2003, sobre el derecho a la reagrupación familiar de refugiados; Directiva 2004/83/CE del Consejo de 29-IV-2004 por la que se establecen normas mínimas relativas a los requisitos para el reconocimiento y el estatuto de nacionales de terceros países o apátridas como refugiados o personas que necesitan otro tipo de protección internacional y al contenido de la protección concedida; Directiva 2005/85/ CE del Consejo de 1-XII-2005 sobre normas mínimas para los procedimientos que deben aplicar los Estados miembros para conceder o retirar la condición de refugiado; Directiva 603/2013/32/UE del Parlamento Europeo y del Consejo, de 26-VI-2013, sobre procedimientos comunes para la concesión o la retirada de la protección internacional; Reglamento "Dublín III" (UE) n. 604/2013 del Parlamento Europeo y del Consejo de 26-VI-2013 por el que se establecen los criterios y mecanismos de determinación del Estado miembro responsable del examen de una solicitud de protección internacional presentada en uno de los Estados miembros por un nacional de un tercer país o un apátrida; por último 
Los refugiados son personas con derechos y, por consiguiente, los Estados tienen obligaciones para con ellos. La mencionada Convención de 1951 obliga a los Estados a garantizar los derechos fundamentales y la protección a las personas refugiadas, lo que implica que no se les puede expulsar ni devolver a los países de los que huyen, se les ha de dar acceso a asilo, se les ha de atender con procedimientos justos y eficientes, se les debe proporcionar condiciones de vida dignas y se les ha de ofrecer seguridad en los países de acogida mientras encuentran una solución a largo plazo.

En el caso de los migrantes no hay una amenaza directa a su vida, sino una búsqueda de trabajo o la reagrupación familiar, manteniendo siempre la posibilidad de regreso a sus países de origen. Para los gobiernos esta distinción es importante. Los países tienen responsabilidades específicas hacia los solicitantes de asilo en su territorio y sus fronteras. Intercambiando los dos términos se desvía la atención de la protección jurídica específica que los refugiados necesitan y se puede socavar el apoyo público para ellos, debido a las circunstancias de su situación particular, aunque de hecho hemos de reconocer que las personas que han llegado a Europa en estos dos últimos años pertenecen a ambos grupos: migrantes y refugiados.

Ante tantas páginas escritas sobre la ya conocida como "crisis de los refugiados", nos hemos sentido llamados a proporcionar tan sólo algunas perspectivas sobre esa realidad que nos son más cercanas. En este tema, como en tantos otros, la información nos llega sesgada y ponderada según unos intereses no siempre transparentes ni legítimos. Los medios de comunicación social -y nuestra revista lo es- tenemos una gran responsabilidad en este campo, pues a los medios compete desenmascarar estereotipos y ofrecer informaciones correctas en las que habrá que denunciar errores de unos y describir y valorar las actitudes de otros, muchas de ellas políticas o moralmente ejemplares. Todos necesitamos un cambio de actitud hacia los refugiados y los migrantes, necesitamos el paso de una actitud pasiva o recelosa, de desinterés o de marginación ("cultura del rechazo") a una actitud de solidaridad desde la interdependencia ("cultura del encuentro"), la única con la que podemos contribuir a construir un mundo equitativo y en paz (Mensaje del papa Francisco para la Jornada mundial del emigrante y del refugiado 2014, 5-VIII-2013).

en el marco español hay que hacer referencia a la Constitución española (art. 13) y a la Ley 12/2009 de 30-X-2009, reguladora del derecho de asilo y de la protección subsidiaria. 


\subsection{La situación de los solicitantes de asilo}

Finalmente, para concluir esta parte descriptivo-analítica, exponemos unas notas sobre otro aspecto particular, pero muy relacionado con el tema de los refugiados, que es el de los solicitantes de asilo a los que nos hemos referido en cuanto potenciales refugiados o en cuanto migrantes, por lo que su estatuto a veces presenta alguna confusión.

Un informe de 2015 de la Comisión española de ayuda al refugiado (CEAR) recogía los principales datos relativos a los solicitantes de asilo en diferentes ámbitos. En el mundial, las solicitudes de asilo en los 44 países más industrializados han pasado de 334.484 en 2007 a 866.087 en 2014. En Europa el incremento fue de un 44\% entre 2013 y 2014. En España el número de solicitantes de asilo en 2013 fue de 4.502 personas frente a los 5.947 solicitantes de asilo en 2014 , los que supone una tasa de variación del $32 \%$, por debajo de la media europea.

Los cinco países del mundo que recibieron más solicitudes de asilo en 2014 fueron: Alemania (173.070), EEUU (121.160), Turquía (87.820), Suecia (75.090) e Italia (63.660). Atendiendo a las decisiones de asilo en Europa y al índice de resoluciones positivas, cabe destacar que en 2014 un $45,2 \%$ de las decisiones de asilo en la UE fueron resueltas positivamente. Cabe destacar que en el grupo de países que más solicitudes reciben, por encima de la media en cuanto a resoluciones positivas están Suecia $(76,8 \%$ de decisiones de asilo resueltas positivamente), Suiza $(70,7 \%)$ o ltalia (58,5\%), mientras por debajo de la media europea están Alemania $(41,7 \%)$, Reino Unido $(38,8 \%)$ o Francia $(21,7 \%)$, así como España, ligeramente por debajo de la media europea pues el $43,8 \%$ de las resoluciones de asilo fueron positivas, siendo éste el desglose de las provincias y ciudades autónomas que registraron un mayor número de solicitudes en 2014: Madrid (1.861 solicitudes), Barcelona (690), Melilla (539), Valencia (473) y Ceuta (394).

Tanto en Europa como en España, al igual que sucede mundialmente, Siria encabeza la lista de países de origen de los solicitantes de asilo, seguida a nivel mundial de Iraq, Afganistán, Serbia, Eritrea y Paquistán, por citar los primeros países de origen. Europa recibe, además de las solicitudes de sirios, principalmente solicitudes de ciudadanos de Serbia, Afganistán, Eritrea, Paquistán y Nigeria. En España las solicitudes proceden sobre todo de ciudadanos de Ucrania, Malí, Argelia, Palestina y Nigeria.

Detrás de estos flujos de personas están los conflictos armados, como la principal causa reconocida por los expertos. Los detonantes de dichos conflictos según ACNUR 
se resumen en tres grandes tipos, económicos, en concreto, la falta de acceso a los recursos básicos como los alimentos, el agua o la energía y las brechas de desigualdad, político-ideológicos y religiosos.

Los expertos difieren en la calificación de un conflicto como guerra, la postura más común es la que considera que para que un conflicto sea considerado guerra tiene que haber al menos 1.000 muertos al año, por debajo de esta cifra se habla de conflicto de media o baja intensidad. En lo que sí parece existir más consenso entre los expertos es en entender el conflicto como un elemento sustancial a la naturaleza humana, por lo que es ingenuo pensar en que es posible alcanzar una paz total, lo que sí se producen son progresos y por eso hay que trabajar en la solución de estos conflictos. ${ }^{12}$

Si bien la cifra actual sobre el número de refugiados en el mundo es la más alta desde la segunda guerra mundial, pues más de 50 millones de personas están desplazadas por culpa de los conflictos armados, la mitad de ellos niños, lo cierto es que el número de guerras se ha reducido en los últimos quince años. En 1990 se contabilizaban 50 guerras en el mundo, mientras que en 2013 había 32, con un ligero repunte en 2011 (37 guerras) debido a la llamada primavera árabe. Los principales conflictos se encuentran en Siria, Sur Sudán, República Centroafricana, Nigeria, República Democrática del Congo, Afganistán, Pakistán e Irak, que se constituyen así en los principales países de origen de los refugiados.

\section{Europa ante los refugiados}

\section{I. Los refugiados muestran la crisis del proyecto europeo de integrar la diversidad}

La mirada desproporcionada de la UE hacia los refugiados es una expresión más de su propia crisis. No es el objeto de este editorial analizar la crisis del proyecto de la UE, del que nos ocuparemos en otro futuro editorial dedicado a la construcción europea, pero lo cierto es que la actitud de Europa, de los Estados que la integran y

\footnotetext{
${ }^{12}$ Análisis realizado a partir de la exposición de Jesús A. Núñez Villaverde, codirector del Instituto de estudios sobre conflictos y acción humanitaria (IECAH), creado en 2000 como centro de investigación que agrupa a un conjunto de especialistas en los ámbitos del estudio de los conflictos y la cooperación con especial énfasis en la ayuda humanitaria. Cf. http://www.iecah.org/
} 
de sus ciudadanos ante la realidad de los refugiados es una manifestación más de esta crisis de proyecto. Europa se enfrenta a una crisis multifactorial: institucional, axiológica, jurídica, política y espiritual.

Todo ello ha desembocado en un repliegue hacia lo nacional y el desapego de la ciudadanía respecto al proyecto de la UE que muestra la incapacidad de respuesta de Europa ante la llamada de los refugiados.

A su vez, la actuación de la UE en este tema se ha visto muy condicionada, ya que Turquía ha aprovechado la debilidad europea para presentarse como un agente indispensable en esta situación, pero también otros factores estructurales como la propia ausencia de política exterior común de la UE han condicionado la capacidad de respuesta europea.

Los refugiados no son el principal problema de la UE, pero han sido la gota que colma el vaso de una creciente preocupación por la seguridad y la identidad europeas $^{13}$. En realidad hay que hablar de dos Europas, la que da la bienvenida a los refugiados y la que, queriendo proteger los derechos nacionales, culturales y de bienestar, aparentemente amenazados por la entrada de refugiados, levanta muros. En este contexto, surgen otros factores que alimentan las posturas del miedo y de rechazo a la entrada de refugiados, como son los recientes actos terroristas en Europa (París, enero y noviembre 2015; Bruselas, marzo 2016; Niza, Wurzburgo y Múnich, julio 2016; Berlín, diciembre 2016).

Aparte de otras razones que apuntaremos, el "problema" de los refugiados en Europa se ha agravado por la rapidez con la que se ha producido la llegada de los mismos (recordemos la situación en Italia, Grecia, etc.) que ha hecho muy difícil una solución. Esto, en parte, es lo que ha determinado que se convierta en un "problema" para Europa; un proceso más lento de llegada de refugiados hubiera sido menos dramático y menos grave, aunque está claro que ninguna sociedad puede elegir el mejor momento para una crisis humanitaria, lo que impide una gradualidad "programada" del proceso.

Puesto que Europa no está actuando como debe y muchos líderes europeos están asustados ante las consecuencias de esta cuestión, ciertamente hemos de acabar concluyendo que éste sí es un problema europeo en la medida en que pone en cuestión la configuración y sentido de la UE.

${ }^{13}$ Cf. CONSEJO de REDACCIÓN (2010) "'La ilusión de la identidad': el actual debate europeo": RFS 65, 13-31. 
Para comprender el papel de la UE queremos abordar las claves de actuación y las políticas de acogida en el ámbito local y estatal. Las soluciones son tan complejas como la realidad que se quiere afrontar. Las claves de actuación son supraestatales y estatales, pero también institucionales, locales y personales. Son claves con connotaciones humanitarias, pero también económicas, políticas y geoestratégicas, jurídicas y ético-filosóficas. Atendiendo a la dimensión temporal son claves operativas, de actuaciones a corto plazo y estratégicas o a largo plazo. En cualquier caso es importante tomar conciencia de que no somos espectadores impotentes. Podemos actuar.

Más allá de una solución, que difícilmente será definitiva, para la realidad de los refugiados, proponemos un objetivo que se resume en esta convicción: puesto que Europa es la patria originaria de los derechos humanos, esta crisis nos plantea exigencias a nosotros, los europeos, sobre nuestra identidad ética y nuestras raíces culturales, humanistas y espirituales (preámbulo del Tratado de Lisboa, 13-XII-2007). Dicho en otras palabras, Europa se juega su credibilidad en este tema.

$\dot{\partial}^{H}$ ay, pues, una crisis del proyecto de la UE? ${ }^{14}$ En este momento en la UE se toman decisiones políticas fuera de las instituciones, por ejemplo por agrupaciones de países por afinidades políticas o geopolíticas. Por otra parte, existe un repliegue emocional e identitario de carácter "nacional" con el consiguiente desapego de la ciudadanía respecto al proyecto de la UE. En la cuestión de los refugiados no hay una política común europea de sus Estados miembro. La perspectiva adoptada es la de seguridad y control de fronteras, expresión de una crisis de principios y valores jurídicos que ha generado una ocasión aprovechada oportunistamente por las mafias, en lugar de garantizar las necesarias vías legales y seguras de acceso a la UE. Por último hemos de constatar que el intento de España de hacer valer su "modelo español" de gestión de la frontera sur, externalizando cínica y duramente el control de fronteras en los países del Magreb, le ha servido como excusa para no asumir mayores compromisos. ${ }^{15}$

${ }^{14}$ Cf. A. Pérez Rubalcaba, "Gran política": El País, 29-VII-2016.

${ }^{15}$ Cf. Boletín de Amnistía internacional, junio 2016. Es cierto que España, al "externalizar" el control de fronteras, lo ha hecho con la connivencia de Marruecos, que al colaborar con España ha reforzado el efecto presentado cínicamente como resultado airoso al presumir de no tener "ese problema". La dura y grave complicidad marroquí no anula no obstante la responsabilidad española. 


\subsection{El Acuerdo de la Unión Europea con Turquía es contrario al derecho internacional}

En la descripción y el análisis que venimos haciendo nos detenemos a continuación en dos consideraciones particulares sobre la UE.

El Acuerdo UE-Turquía de 18-III-2016 ha significado la aprobación de unas medidas que en síntesis son: retorno de migrantes irregulares a Turquía; por cada sirio retornado a Turquía desde las islas griegas se reasentará en países de la UE a otro sirio procedente de Turquía; se evitará que se abran nuevas rutas marítimas o terrestres de migración ilegal desde Turquía a la UE; régimen voluntario de admisión humanitaria; liberalización de visados; desembolso de 3.000 millones de euros de la UE a Turquía y financiación adicional de otros 3.000 millones hasta fin de 2018; perfeccionamiento de la Unión aduanera; compromiso de reactivación del proceso de adhesión de Turquía a la UE; colaboración de UE y los Estados miembro con Turquía para mejorar las condiciones humanitarias en Siria.

Este Acuerdo sobre la devolución de refugiados que hayan ingresado en Grecia desde Turquía, a juicio de algunos juristas ${ }^{16}$, es contrario como Tratado internacional, a la Convención de Ginebra y a la Directiva de Procedimiento 2013/32 para la concesión o retirada de la protección internacional puesto que ha sido aprobado sin seguir los cauces previstos para los "Acuerdos internacionales" en los artículos 216 y siguientes del Tratado de Funcionamiento de la Unión Europea; por otro lado vulnera el artículo 4 del Protocolo 4 del Convenio europeo de derechos humanos, que prohíbe las expulsiones colectivas, a lo que se añade que Turquía no puede considerarse un "país seguro" para los refugiados provenientes de Siria y otros países en conflicto, pues organizaciones internacionales como Amnistía Internacional o Human Rights Watch y organizaciones no gubernamentales, como la Comisión española de ayuda al refugiado (CEAR), tienen documentados casos graves de vulneración de derechos humanos de refugiados sirios por parte de Turquía, Estado que no ha firmado el Protocolo de 1967 a la Convención de

\footnotetext{
16 Diego López Garrido, catedrático de Derecho constitucional y exsecretario de Estado para Asuntos Europeos (2008-2011), autor de El derecho de asilo, Madrid 1991, Trotta, 334 pp, en el que se analiza la naturaleza política del asilo y se defiende ese derecho como factor condicionante de las relaciones internacionales, ha realizado recientemente un análisis del Acuerdo UE-Turquía desde el punto de vista de su naturaleza política, su adecuación al derecho europeo y a la Convención de Ginebra: "Acuerdo UE-Turquía: refugiados sin ley", consultable en http://ctxt.es/es/20160420/Politica/5505/ acuerdo-UE-Turquia-refugiados-inmigracion-grecia-siria-vulneracion-derechos-derecho-asilo.htm
} 
Ginebra, que ampliaba el ámbito geográfico de la Convención más allá de las fronteras europeas.

Desde un punto de vista legal, contra ese Acuerdo, un acto jurídico del Consejo Europeo, cabría un recurso de anulación interpuesto por los directamente afectados ante el Tribunal de Justicia de la UE de Luxemburgo, así como un recurso ante el Tribunal europeo de Derechos humanos de Estrasburgo por violación del Convenio Europeo de Derechos Humanos (Protocolo 4), una vez agotadas las vías judiciales nacionales. Además, hay otras vías "indirectas" para llegar al Tribunal de Justicia de la UE, mediante cuestión prejudicial que pudiese elevar a Luxemburgo un juez nacional en un eventual litigio que un refugiado suscitase contra las autoridades de Grecia.

La gravedad del acuerdo UE-Turquía hay que sopesarla a la luz de la quiebra de los principios y valores de la construcción europea, de la falta de respeto al derecho internacional y, sobre todo, de la dignidad del ser humano, según el análisis que hemos seguido en este apartado.

\section{3. ¿Cómo afecta la realidad a nuestra percepción?}

El análisis de esta realidad estructural, contrastado con los mensajes que recibimos de los medios de comunicación, pone de manifiesto una brecha importante. Por una parte, los medios hacen uso de las imágenes más duras e impactantes de esta cruda realidad, lo que traslada a la sociedad sentimientos de indignación, impotencia, rabia, pero también de solidaridad para ayudar en lo que se pueda y para tomar conciencia de la responsabilidad personal y social y de la de los poderes públicos. Por otra parte, esta información convive con la de los mensajes políticos y las escenas de los campos de refugiados, cuya combinación da como resultado una imagen desproporcionada sobre los refugiados, su número, su impacto en nuestras sociedades y nuestra capacidad de atender la situación. Un espectador no muy informado podría extraer fácilmente la conclusión de que la dimensión del problema es tan grande que Europa no tiene capacidad ni recursos para atenderla. De hecho, la propia Europa ha estado dividida en este tema entre el este y el oeste o, en otros términos, entre el eje Berlín-Bruselas y grupo de Visegrado, formado por Chequia, Hungría, Polonia y Eslovaquia.

Los mensajes de los medios no nos dan proporción ni perspectiva. Como en tantos otros temas, tenemos que apelar a la responsabilidad social de los medios de comunicación para que más allá de las políticas editoriales y de los objetivos de audiencia, trasladen a la ciudadanía una información rigurosa y de calidad. 
Si atendemos a las cifras y tratando de dar proporción a la realidad, estamos hablando de un refugiado por cada 400 europeos, o en relación a la población española un refugiado por cada 2.555 españoles. Si cada uno de nosotros abriéramos las puertas de nuestra casa a la llamada de los refugiados no pasarían con nosotros ni un día al año. El lector podrá juzgar si la realidad coincide con la percepción que tenemos del problema.

No es necesario insistir en que quien realmente está experimentando un periodo de crisis es el proyecto de la UE, cuyas manifestaciones más evidentes, como ya se ha indicado, son el repliegue hacia lo nacional y el desapego de la ciudadanía. Es difícil saber si la respuesta de la UE a la llegada de refugiados hubiera sido otra en otro contexto, aunque la historia nos lleva a pensar que sí. Tampoco podemos pasar por alto el debate sobre la seguridad en Europa, agudizado tras los atentados terroristas del último año en Bruselas, en París, en el sur de Francia y en Alemania.

Ante la falta de una política común de los Estados miembro en esta materia, la perspectiva adoptada es con frecuencia sólo la de seguridad y control de fronteras, expresión de una crisis de principios y valores jurídicos. En estas malas soluciones, España ha tenido su cuota de responsabilidad, en tanto ha intentado hacer valer su modelo de gestión de la frontera sur, a la par que lo ha utilizado como excusa para no asumir mayores compromisos, como ya hemos indicado antes. Todo ello ha generado el espacio idóneo para el desarrollo de las mafias y ha evidenciado la necesidad de establecer vías legales y seguras de acceso a la UE.

La conclusión de este análisis es que realmente no estamos ante una crisis pasajera, una "emergencia", sino ante un problema "estructural" cuya dimensión, siendo importante (cada persona y cada refugiado lo es), no es tan grande como nos quieren hacer ver para justificar determinadas actitudes y políticas de contención de algunos actores públicos (políticos o mediáticos) frente a las políticas de acogida que deberíamos estar desarrollando y de tratamiento de las causas en origen. 


\section{Claves de actuación}

\section{I. Políticas de acogida y modelos de adaptación de las personas refugiadas}

Antes de proponer las conclusiones sobre formas y procesos de acogida, nos parece interesante aproximarnos a los distintos modelos o culturas de relación de la población de origen diferente (refugiados, migrantes, etc.) en/a los países de acogida.

Toda modelización implica una cierta simplificación que es compensada si el modelo ayuda a ganar en claridad analítica para comprensión de la realidad y permite formular propuestas prácticas que transforman las condiciones reales en el sentido pretendido. A partir de los modelos -mixtos o puros- que resultan de la combinación de cuatro variables (identidad de origen / identidad de destino; derecho de ciudadanía / pertenencia nacional), podemos reflexionar y responder a la cuestión del modelo por el que nos pronunciamos para un proceso revisable y adaptado de acogida de los refugiados. ${ }^{17}$

Actualmente se consideran cuatro modelos puros con las posibles combinaciones entre ellos: asimilacionista, segregacionista, multiculturalista e integrador.

El llamado modelo asimilacionista pretende la adaptación del inmigrante (o refugiado) a la sociedad de destino o acogida, superando o eliminando explícitamente las referencias a la sociedad de origen de la que llega; es el modelo francés que subraya el ius soli, el derecho de ciudadanía vinculado a una comunidad política; el modelo segregacionista parte de una vinculación étnica o nacional (cultural) como base de la pertenencia a una sociedad; éste es el modelo alemán que acoge desde la diferencia, subrayando el ius sanguinis, es decir, el hecho de que el derecho nace de la vinculación a una comunidad de origen que se mantiene independientemente del lugar de vida; como se ve, en su estado puro, esta concepción es radicalmente diferente de la anterior; el modelo multiculturalista, predominante en el mundo anglosajón, parte de que las comunidades se adaptan de hecho, sin necesidad de una regulación expresa, pues basta la convivencia paralela o yuxtaposición de

\footnotetext{
${ }^{17}$ Sobre la problemática de las migraciones: J. L. MARTíNeZ MARTíneZ (2006) "Pensar la integración de los inmigrantes: la sociedad española al comienzo del siglo XXI": Revista de Fomento Social 61, 361-392; ID. (2007) "Educar para la convivencia intercultural e interreligiosa: Pentecostés frente a Babel", en Jornadas educativas Misión educativa e inmigración, CONEDSI, Granada, 10 a 12-VII-2007, 57-120; J. M. MARGenat (2007) "La inmigración y la misión educativa de la Compañía", ibid., 121-141. Los modelos de integración están inspirados en J. W. BERRY (1992) "Acculturation and Adaptation in a New Society": International Migration 30, 69-85.
} 
diferentes comunidades que conservan sus vínculos con sus sociedades de origen, aunque conviven en un melting pot; por último, hay un modelo que podríamos pensar desde una aculturación integradora a partir de la relación intercultural, que busca un diálogo y relación entre las diferentes culturas presentes, respetando las identidades sin asimilar ni segregar, aunque buscando los elementos compartidos que favorezcan un mestizaje real; es un modelo que en cierta manera encontramos en sociedades latinas como Italia, España o Argentina, aunque como modelo expresamente formulado y evaluado se da expresamente en Canadá por lo que podríamos denominarlo también modelo canadiense intercultural.

\section{CUADRO I. Modelos de “adaptación”}

\begin{tabular}{|c|c|c|c|c|c|c|c|}
\hline Alemania & ius sanguinis & \multirow{3}{*}{$\begin{array}{c}\text { Conservación } \\
\text { de la } \\
\text { identidad } \\
\text { de origen }\end{array}$} & \multirow[b]{2}{*}{ Sí } & \multirow{2}{*}{$\begin{array}{l}\text { Segregación } \\
\text { multicultural }\end{array}$} & \multirow{2}{*}{$\begin{array}{l}\text { Integración } \\
\text { Aculturación } \\
\text { intercultural }\end{array}$} & & \multirow[b]{2}{*}{ Canadá } \\
\hline \multirow[t]{4}{*}{ Inglaterra } & $\begin{array}{l}\text { multicultural melting pot } \\
\text { (crisol anglosajón postcolonial) }\end{array}$ & & & & & & \\
\hline & & & NO & Marginación & Asimilación & \begin{tabular}{|l|} 
ius soli- \\
laicidad republicana
\end{tabular} & Francia \\
\hline & & & & NO & SÍ & & \\
\hline & & & & \multicolumn{2}{|c|}{$\begin{array}{l}\text { Adquisición de una nueva } \\
\text { cultura e identidad }\end{array}$} & & \\
\hline
\end{tabular}

Fuente: J. W. BERRY (1992) art. cit. Elaboración, ampliación y modificación de RFS.

\subsection{Los tiempos de desarrollo de las políticas de acogida}

Para la discusión, sensibilización, implantación y desarrollo de los modelos presentados hace falta también una adecuada gestión de los tiempos, según la conocida expresión, usada alguna vez por papa Francisco: el tiempo es superior al espacio, y lo esencial es generar procesos de cambio cada vez más asumidos y consolidados. Podemos distinguir tiempos a corto, a medio y a largo plazo.

A corto plazo es obvio que hay que actuar en tres aspectos o direcciones diferentes; lo necesario en ese plazo es la atención a aquellas situaciones de emergencia, con el refuerzo de las estructuras de recepción y la realización de gestos de acogida y campañas de sensibilización cultural, sea en los ámbitos educativos, en las comunidades religiosas de distintas confesiones o en la opinión pública.

Como ejemplo de acciones a corto plazo, el tiempo en el que la prioridad es salvar vidas, exponemos las ochos propuestas que ha hecho Amnistía Internacional para que los Estados den pasos para resolver esta crisis: 
1. Abrir rutas sin riesgos a un lugar seguro. Esta medida supone permitir que las personas se reúnan con sus familiares y proporcionarles visados para que no tengan que gastar los ahorros de toda su vida ni arriesgar sus vidas para llegar a un lugar seguro, al mismo tiempo que así se cortaría el negocio de las mafias.

2. Reasentar a todas las personas refugiadas que lo necesiten, especialmente a las más vulnerables como los enfermos o los supervivientes de torturas.

3. Invertir recursos en operaciones de búsqueda y salvamento, prestando de inmediato ayuda a las personas en dificultades.

4. Permitir cruzar las fronteras a aquellas personas que huyen de situaciones de persecución o de guerra y facilitarles las solicitudes de asilo.

5. Investigar y enjuiciar a las bandas de traficantes que explotan a las personas refugiadas y migrantes.

6. Combatir todos los tipos de xenofobia y discriminación racial.

7. Cumplir con los compromisos económicos de los Estados de proporcionar fondos para la ayuda a las personas refugiadas. En concreto, Amnistía Internacional declara que la ONU ha recibido menos de la mitad de los fondos que necesita para ayudar a los casi cuatro millones de personas refugiadas de Siria.

8. Recuperar la memoria histórica. Tras la segunda guerra mundial, la mayoría de los países acordaron proteger a las personas refugiadas por medio de la Convención sobre el Estatuto de los Refugiados de 1951 y de organismos de la ONU como ACNUR. Frente a las vallas y las políticas de contención es necesario que los Estados establezcan sistemas sólidos de atención a las personas refugiadas.

A medio plazo la actuación debe centrarse en una acción continuada y cada vez más profunda, constantemente evaluada, de educación y sensibilización de la opinión pública, seguimiento y fomento de las negociaciones de paz de la comunidad internacional y apoyo al desarrollo económico de los pueblos.

A largo plazo la acción debe orientarse a consolidar procesos de integración duraderos e irreversibles y a resolver las causas de los problemas en su raíz. Las soluciones a largo plazo pasan por poner fin a los conflictos y la persecución que obligan a las personas a huir, así como por todas las políticas económicas que persiguen el desarrollo económico de los pueblos y la reducción de las des- 
igualdades y aquellas políticas educativas que persiguen una formación para la ciudadanía global, una educación para el desarrollo y la solidaridad, acabando con la cultura de la indiferencia.

\subsection{La contribución desde la Compañía de Jesús para resolver la cuestión}

No podemos abordar la realidad de los refugiados y más en general de las migraciones y las posibles líneas de actuación que se abren, sin hacer referencia a la labor que la Compañía de Jesús ha venido realizando desde hace tiempo así como de las iniciativas de trabajo más recientes. El Servicio Jesuita a Refugiados (JRS, de sus siglas en inglés) fue creado a iniciativa del padre Arrupe, entonces prepósito general de la Compañía de Jesús, en 1980. Desde entonces, fiel a su lema Acompañar, Servir y Defender, ha realizado una importante labor que hoy sigue siendo apoyada y completada por otras organizaciones jesuitas.

Entre las iniciativas más reciente, puestas en marcha tras la llamada "crisis de los refugiados" destaca la campaña "Yo soy Tierra de Acogida", concebida como una respuesta integral compuesta por cuatro elementos:

- Comunidades de hospitalidad

- Cooperación internacional y apoyo al Servicio Jesuitas a Refugiados

- Sensibilización y comunicación

- Incidencia

Las comunidades de hospitalidad son un modelo de acogida que ya está en marcha y que promueven la integración comunitaria de los refugiados y migrantes, generando lazos humanos entre aquellas y éstos. A ello se une el apoyo internacional en países de origen y tránsito y la cooperación. En tercer lugar, se trata de extender en la ciudadanía actitudes de hospitalidad y acogida y, en cuarto, en colaboración especialmente con las universidades, ir constituyendo una agenda propia y compartida de todas las organizaciones implicadas en este servicio. Esta respuesta se basa en los principios de universalidad -no distinguir entre refugiados y resto de migrantes-, mayor necesidad-atender las necesidades menos cubiertas y los espacios de mayor vulnerabilidad-, ampliación del foco, tanto en lo geográfico como en la integralidad de las respuestas y trabajo de incidencia en red con otras entidades eclesiales y sociales de forma apasionada y discernida, lo que implica organización, coordinación y tiempo.

A partir de esos criterios, las entidades vinculadas a la Compañía de Jesús han formulado los objetivos propios para su acción coordinada: 
1. Salvar vidas, reforzando las operaciones de salvamento marítimo en España y en el Mediterráneo. Salvar vidas es prioritario y cuanto más se cierran las fronteras, más peligrosas se hacen las rutas.

2. Abrir vías de acceso, impulsando las que sean legales y seguras, para impedir el lucrativo negocio de las mafias, agilizar y flexibilizar las posibilidades de reunificación familiar, la emisión de visados humanitarios o las solicitudes de asilo en consulados españoles.

3. Cumplir con el compromiso de reubicar a 16.000 personas refugiadas desde Grecia e Italia e impulsar a que los otros estados miembros de la Unión Europea también cumplan las cuotas a las que se han comprometido.

4. Hacer efectivo el compromiso de reasentar 1.449 personas refugiadas.

5. Conceder asilo con procedimientos individualizados, rápidos, justos, y eficientes, sea cual sea el país de origen o de llegada.

6. Tratar a las personas que llegan con dignidad y respeto a sus derechos, independientemente de su estatus migratorio.

7. Anular el acuerdo de la UE con Turquía.

8. Reforzar la ayuda humanitaria, destinando el $0,4 \%$ de la renta nacional bruta a ayuda oficial al desarrollo en la próxima legislatura y destinar el 10\% de la ayuda oficial al desarrollo a ayuda humanitaria.

9. Contribuir a la paz y abordar las causas estructurales y globales del creciente éxodo de personas (adultos y niños) que abandonan involuntariamente sus hogares.

10. Posibilitar la integración de los refugiados, brindando soluciones duraderas y adecuadas para su acogida en nuestro país.

11. Fomentar una cultura de la hospitalidad desde las distintas políticas públicas implicadas, incluyendo la educación para la ciudadanía global como estrategia para que las sociedades de acogida comprendan las causas de los desplazamientos, prevengan la radicalización social y fomenten la convivencia intercultural. 


\section{Conclusión}

Los refugiados son una realidad estructural de nuestro mundo que vive una situación persistente y duradera de éxodo planetario. No estamos ante una crisis temporal ni sólo ante una emergencia. En realidad, estamos ante una crisis de valores, pues como generación estamos viviendo un desafío vital para Europa. Como escribía recientemente, en vísperas de la primera cumbre de la UE sin el Reino Unido, Jacques Delors:

En este período de crisis de identidad europea, es esencial para la UE mostrar que no está paralizada, sino dispuesta a actuar como fuerza de primer orden en la lucha contra los desafíos mundiales del cambio climático, del aumento de las desigualdades y a favor de un desarrollo duradero e inclusivo, para promover los derechos humanos y para asegurar que nadie será dejado el margen. ${ }^{18}$

La miopía histórica podría recluirnos en los muros domésticos, ante flujos humanos mundiales provocados por situaciones que muestran la interdependencia cada vez mayor de todas las dimensiones de la realidad: la economía mundializada, la ecología integral, la seguridad global.

La defensa de nuestro conocido como Estado social del bienestar no puede ser el umbral de nuestra solidaridad, pues esto supondría dar de lo que nos sobra tan sólo a partir de lo seguro. Nuestro Estado social y democrático de derecho nacido en la Europa de la posguerra se funda sobre los principios de paz y justicia en un tiempo precedido inmediatamente por una noche de guerra destructora, de exterminio de grupos étnicos, culturales y religiosos, de violaciones masivas de los derechos humanos y de movimientos migratorios que Europa no conocía desde hacía siglos y no ha vuelto a conocer hasta los más recientes años. Nuestra solidaridad no empieza donde acaba nuestro bienestar, sino que precisamente porque éste se funda en aquella, la solidaridad d debe ser inclusiva de los refugiados, los inmigrantes, los desplazados y los empobrecidos. Concretamente, Europa necesita además definir una política europea global de migraciones que sea fiel reflejo de sus valores fundacionales. Precisamente es la defensa y sostenibilidad inclusiva de ese Estado social y democrático de derecho con la economía social de mercado, solidaria y competitiva, las que ponen delante de nosotros un desafío que va a cambiar Europa y va a cambiar la vida de nosotros como personas y como ciudadanos. Ésta era la reflexión de la canciller alemana Angela Merkel:

${ }^{18} \mathrm{Cf}$. J. Delors (2016) "Aux jeunes générations de faire revivre les valeurs des fondateurs": Le Monde, Paris, 14-IX-2016 (fechado el 15), 20. 
Lo que vivimos ahora nos seguirá ocupando en los próximos años. Nos cambiará. Queremos que el cambio sea positivo y pensamos que podemos lograrlo. ${ }^{19}$

No sólo el Estado social europeo está en crisis, sino que las líneas de fractura atraviesan también la presión sobre el espíritu de Schengen, la solidaridad interterritorial y la libertad de movimientos de los ciudadanos europeos y de que quienes han llegado a esta tierra de acogida.

Para concluir nos permitimos apuntar algunas pistas para pensar y lograr un cambio positivo que ya ha comenzado:

1. La conciencia de que Europa como espacio privilegiado para la esperanza humana (preámbulo del Tratado de Lisboa) es un espacio-refugio mundial que buscan millones de personas, es una llamada a recuperar nuestras raíces espirituales, éticas y humanistas para reconstruir nuestro proyecto.

2. La negociación y el diálogo, expresión de la voluntad política, la coordinación y el trabajo en red de instituciones públicas y privadas, se configuran como condiciones necesarias, aunque nunca suficientes.

3. Un amplio consenso europeo para la elaboración de políticas de acogida a los refugiados y de asilo que sean eficientes y garantistas, complementadas por políticas migratorias innovadoras es necesario.

4. Los beneficios y oportunidades que los migrantes y los refugiados suponen, en cuanto población joven (muchos de ellos con muy buena formación) para la reversión de la decadente dinámica demográfica europea de envejecimiento y para la garantía y sostenimiento del Estado social y sus prestaciones deben ser valorados.

5. Este tiempo también puede ser propicio para poner de manifiesto las posibilidades de respuesta de las redes de instituciones eclesiales que han sido un signo de una solidaridad crítica y responsable. ${ }^{20}$

6. La oportunidad de transformar las políticas nacionales en supranacionales

${ }^{19} \mathrm{Cfr}$. Le Nouvel Observateur. 3-IX-2016.

${ }^{20}$ Cf L. Estepa y J. M. MARgenat "Una sola familia humana: hospitalidad y derechos humanos de las personas inmigrantes": RFS 70 (2015) 593-601. 
podría tener un efecto positivo en Europa, ayudando a salir a las poblaciones europeas de su ensimismamiento identitario, al igual que el cambio demográfico que ya está presente nos lleva a un modelo cultural mestizo y a dejar de ser ciudadanos de un país para pasar a ser ciudadanos del mundo.

Las dificultades con que nos encontramos para acabar con las causas que originan la salida de ciudadanos de sus países de origen, que reconocemos, en concreto, los conflictos bélicos y las otras a que hemos hecho referencia, nos hacen ser prudentes con las expectativas de solución ante este desafío. Tenemos que convivir con los problemas estructurales, sabiendo que aunque la solución definitiva esté lejos, lo que dota de sentido a nuestra tarea es el propio trabajo diario, como máxima expresión de la solidaridad humana y de la esperanza.

Para responder creativa y positivamente al desafío que los refugiados hacen a Europa, hace falta un liderazgo y parece que el de Angela Merkel, cuestionado por algunos, pero valiente y firme, ofrece el único horizonte a partir del cual pensar una política común de asilo europeo como gran proyecto que nos ponga ante el reto de saber si como ciudadanos europeos y como Estados de la UE somos realmente capaces de tomar medidas conjuntas ${ }^{21}$.

Comenzábamos este editorial con una frase del papa Francisco y concluimos con su expresión de denuncia y de esperanza:

Europa es la patria de los derechos humanos,

y cualquiera que ponga pie en suelo europeo debería poder experimentarlo. ${ }^{22}$

\footnotetext{
${ }^{21}$ Angela Merkel, 16-VIII-2015.

22 Papa Francisco en su visita a la isla griega de Lesbos, 16-IV-2016.
} 